\title{
Shallow 3-D Vertical Seismic Profiling Around a Contaminant Withdrawal Well on the Lawrence Livermore National Laboratory Site
}

\author{
J. Rector \\ R. Bainer \\ P. Milligan \\ C. Tong
}

January 30, 1997

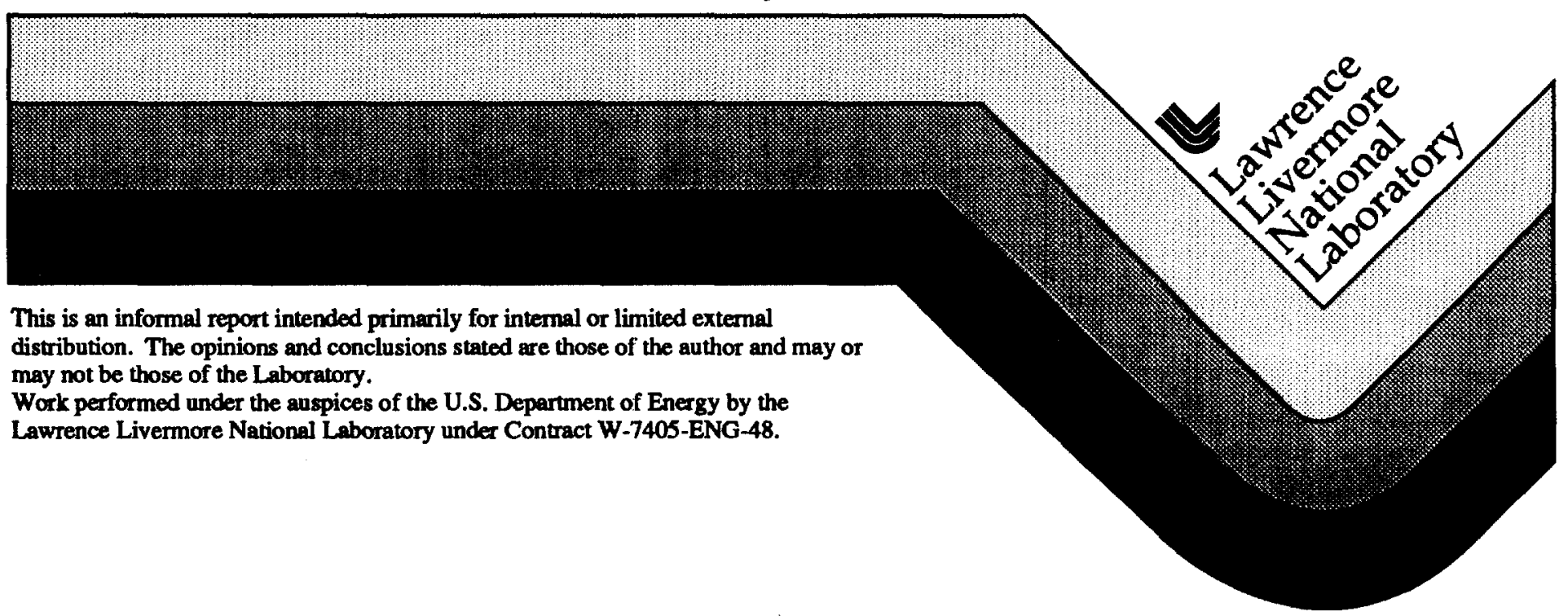




\section{DISCLAIMER}

This document was prepared as an acccount of work sponsored by an agency of the United States Covernment. Neither the United States Government nor the University of Callfomia nor any of their employees, makes any warranty, express or implied, or assumes any legal liability or responsibility for the accuracy, completeness, or usefulness of any information, apparatus, product, or process disclosed, or represents that its use would not infringe privately own rights. Reference herein to any specific commercial products, process, or service by trade name, trademark, manufacturer, or otherwise, does not necessarily constitute or imply its endorsement, recommendation, or favoring by the United States Government or the University of California. The views and opinions of authors expressed herein do not necessarily state or reflect those of the United States Government or the University of California, and shall not be used for advertising or product endorsement purposes.

This report has been reproduced directly from the best available copy.

Available to DOE and DOE contractors from the Office of Scientific and Technical Information

P.O. Box 62, Oak Ridge, TN 37831

Prices available from (615) 576-8401, FTS 626-8401

Available to the public from the National Technical Information Service

U.S. Department of Commerce 5285 Port Royal Rd. Springfield, VA 22161 


\title{
Shallow 3-D Vertical Seismic Profiling Around a Contaminant Withdrawal Well on the Lawrence Livermore National Laboratory Site
}

\author{
James Rector, Robert Bainer, Paul Milligan, and Carol Tong
}

\section{Introduction}

One of the major problems associated with ground water contaminant remediation is well placement. Optimal placement of wells requires an accurate knowledge of geologic structure and stratigraphy in the near surface sediments and rock $(0$ to $100 \mathrm{~m})$. Without the development of remote imaging provided by geophysical techniques, the required spacing between treatment wells may be less than $2 \mathrm{~m}$ in order to be confident that all contaminant reservoirs had been remediated.

One method for characterizing geologic structure and stratigraphy in the near surface is vertical seismic profiling (VSP), a technique often used on deep exploration wells to calibrate surface seismic reflection data. For nearsurface applications, VSP data can be acquired efficiently using an array of hydrophones lowered into a fluid-filled borehole (Milligan et al, 1997). The VSP geometry overcomes some of the limitations of conventional nearsurface seismic reflection imaging such as surface noise (both cultural and shot-generated) and statics, and can provide sub-meter resolution in some instances (Milligan, et al, 1997).

When performed using source positions located around the receiver borehole (Figure 1) the reflection arrivals from a VSP can be processed to yield a three dimensional (3-D) subsurface view in the vicinity of the borehole. One of the limitations of vertical seismic profiling for shallow imaging is the lateral coverage away from the borehole, which is limited to about $1 / 3$ of the target depth. However, by performing surveys around a group of wells (Figure 2), the areal coverage of 3-D VSP can be expanded. This geometry is novel in conventional exploration well VSP because the cost of rig time and the absence of large (greater than 10 channel) receiver arrays makes 3-D VSP prohibitively expensive in most instances. By contrast, for shallow applications well costs are small, and large ( 24 and 48 element) hydrophone arrays are commercially available.

In this paper we discuss the acquisition and processing of a 3-D VSP collected at a shallow remediation site located on the grounds of the Lawrence Livermore National Laboratory (LLNL) near Livermore, California. Lawrence Livermore National Laboratory is a research and development facility owned by the United States Department of Energy and operated by the University of California. In the mid- to late-1940s, the site was used by the United States Navy as an air training base. At this time, initial releases of 
hazardous materials to the environment occurred in the form of solvents [volatile organic compounds (VOCs)] that were used for the cleaning of airplanes and their parts. Gasoline, diesel and other petroleum -based compounds are also known to have leaked into the ground. California Research and Development Company, a subsidy of Standard Oil, occupied the southeastern portion of the site from 1950 to 1954. The first releases of radioactive materials to the environment occurred at this time, with the beginning of testing of radioactive materials at the site. In 1952, LLNL acquired the site. Additional releases of VOCs, polychlorinated biphenyls (PCBs), metals, radionuclides (primarily tritium), gasoline and pesticides have occurred since. These releases were due to localized spills, landfills, surface impoundments, disposal pits, broken sewer lines and pipes, and leaking tanks.

\section{Overview of Remediation and Site Geology at LLNL}

The ground water and vadose zone contaminants of primary concern at LLNL are VOCs, tritium, gasoline, and metals that exceed State and Federal Regulatory Limits. VOCs, predominantly perchloroethylene (PCE) and trichloroethylene (TCE), are the most widespread contaminants of concern at LLNL. The VOCs occur in ground water in relatively low concentrations (generally less than one part per million (ppm) over the majority of the site) and underlie about $85 \%$ of the LLNL site. Numerous small plumes with various contaminant signatures, with independent sources, coalesce into the broader site-wide ground water plume. The ground water plume encompasses a total area of about 1.4 square miles. The vertical thickness of the VOC ground water plumes vary from about 10 to $30 \mathrm{~m}$, and VOCs are seldom found beneath a depth of about $60 \mathrm{~m}$.

Remediation of contaminated sediments and ground water have been ongoing since 1988. The preferred method of remediation has been to install recovery wells, pump the contaminated water to a treatment facility where the volatiles are air stripped and then the treated water is recycled into the aquifer, surface water, or used for irrigation. Insufficient understanding of the heterogeneity of the subsurface geology at LLNL is one of the main difficulties in designing the ground water recovery systems.

Contaminants are distributed within a thick sequence of alluvial sediments that consist of complexly interfingered sand and gravel channel deposits within lower-permeability silt and clay. These higher permeability channel deposits are pathways for VOC transport. Understanding the impact of the distribution of these channel deposits is critical for effectively implementing the ground water cleanup; however, due to their complex geometry, it is difficult to trace individual channels laterally. Some of these channel deposits that appeared distinct and separate from borehole log data were actually hydraulically connected, whereas other channel deposits had 
little or no hydraulic connection. Hydraulic interconnection between or within permeable layers is measured directly from response to ground water pumping, or inferred indirectly from VOC concentrations or hydrographs. Packages of sediments whose permeable layers showed evidence of hydraulic communication are grouped together into a single hydrostratigraphic unit (HSU). The significant regional or local aquitards are then defined as separate HSUs. Minor aquitards define HSU boundaries across which little or no vertical hydraulic communication was observed from aquifer tests.

\section{3-D VSP Acquisition Overview and Local Geology: Well W-1206}

Figure 3 illustrates a cross-section through well W-1206, with gammaray and resistivity logs from the three wells located along $\mathrm{AA}^{\prime}$. Well W-1206 penetrated HSUs 2 through 5 under saturated conditions. HSUs 2 and 4 are the primary targets for remediation, and their distribution and connectivity have been confirmed with hydraulic tests. HSU-2 is present from 63 to $111 \mathrm{ft}$ and consists of an interbedded sequence of sands, silts and clays. The upper $20 \mathrm{ft}(63-82 \mathrm{ft})$ and the lower $10 \mathrm{ft}(101-111 \mathrm{ft})$ are predominantly fine to coarse grained, loosely consolidated sands, and can be correlated several hundred feet from the borehole. HSU-3 has been subdivided into two subunits based on hydraulic test data. HSU-3A is present from 111 to $143 \mathrm{ft}$ and HSU-3B is present from 143 to $173 \mathrm{ft}$. Both consist of interbedded sequences of sands, silts and clays, with HSU-3A exhibiting greater permeability and coarser grained materials. HSU-4 is present from 173 to $187 \mathrm{ft}$ and consists of highly permeable, silty gravels and sands whose distribution is indicative of meandering stream deposition. The channel(s) exhibit a high degree of lateral hydraulic communication, but are not present uniformly across the area. As shown in Figure 3, approximately 15 degrees of dip to the southwest has been inferred in the log correlation between wells W-1206 and W-351. One of the principal goals of the 3-D VSP survey was to image the HSU boundaries particularly HSU 4, which was considered the most laterally variable, and characterize the structure and continuity of the HSU boundaries away from W-1206.

Figure 4 is a map view along with source locations used for the 3-D VSP experiment. We selected to acquire the VSP data in a cylindrical geometry, with sources along equi-offset radials from the wellhead. Using this geometry, common-source-offset data from different azimuths can be compared. By contrast, comparison of VSP data from different source offsets is made more difficult by changes in the arrival incidence angle, which influences factors such as reflection amplitudes, P-to-S wave conversion coefficients, raybending, and wavefield separation artifacts. By minimizing changes in incidence angles from azimuth to azimuth, geologic effects can be separated from wavefield effects. As shown in Figure 4, the coverage is not uniform. Several source locations, particularly the longer offsets in the northwest quadrant could not be obtained due to the presence of buildings. 
Before the complete 3-D VSP survey was acquired, energy source tests were done to estimate the optimal offsets and source types. Three different sources were compared a $10 \mathrm{lb}$ sledge hammer-on-plate stacked $\mathrm{n}$ times, a single betsy gun lowered into a $1 \mathrm{~m}$ fluid-filled hole, and a Bison Elastic Wave Generator (EWG) weight-drop source stacked $k$ times. The data were recorded by a 48 level hydrophone array with $0.5 \mathrm{~m}$ spacings between the hydrophones. Closed-cell foam was attached between the hydrophone elements to attenuate tube wave arrivals (Milligan, et al, 1997).

The EWG source exhibited the highest signal-to-noise ratio followed by the hammer-on-plate and finally by the Betsy Gun source. The hammer-onplate source did exhibit slightly higher frequency content (up to $250 \mathrm{~Hz}$ ) than the EWG source $(210 \mathrm{~Hz})$. It is interesting to note that the frequency content at LLNL is substantially lower than frequencies reported by Milligan et al (1997) at a nearby site. The difference in frequency content can probably be attributed to the difference in water table depth. At the bay margin site discussed by Milligan et al (1997), the water table was $2 \mathrm{~m}$, whereas at well W-1206 the water table was $25 \mathrm{~m}$. VSPs conducted across the LLNL site, where the water table can vary from $10 \mathrm{~m}$ to $30 \mathrm{~m}$, have shown that the maximum frequency is primarily controlled by the water table level. For hydrophones located between 26 and $49 \mathrm{~m}$ the optimal offsets for VSP data were between 10 and 30 $\mathrm{m}$. For offsets larger than $30 \mathrm{~m}$ VSP data with very weak direct arrival signal were observed.

Based on the results of the source test, 3-D VSP data were acquired with offsets ranging from $10 \mathrm{~m}$ to $30 \mathrm{~m}$ and the uppermost hydrophone located just below the top of the fluid column at $26 \mathrm{~m}$ in well W-1206. The EWGsource data, 100 sources by 48 hydrophones $=4800$ traces, were collected in an afternoon. This geometry provided an imaging radius around the borehole of about $10 \mathrm{~m}$. Figure 6 shows VSP data from the different offsets along a representative azimuth. Note the decrease in direct arrival moveout with increasing offset indicating a more vertical wavefront. Also note the low velocity zone at $36 \mathrm{~m}$. This zone is particularly apparent at the longer offsets. Besides the direct and reflected arrivals, strong tube waves reflected from the bottom of the hydrophone array are also apparent in the data. The insertion of the foam baffles between the hydrophone elements slows the tube wave arrival down to an velocity of about $120 \mathrm{~m} / \mathrm{s}$ (Milligan, et al, 1997).

\section{Velocity Field Generation}

Velocity functions were generated for each shot azimuth as follows:

1) A starting 1-D velocity model was generated from a zero-offset VSP collected using a single vertical geophone clamped at $1 \mathrm{~m}$ intervals (above $25 \mathrm{~m}$, only two positions were collected). 
2) The data were datum-corrected so that for a particular offset, the traveltime to the shallowest hydrophone was constant.

3) The first break times were picked.

4) The first-break times were compared to raytrace-modeled traveltimes produced from the 1-D starting model using the $5 \mathrm{~m}$ and $10 \mathrm{~m}$ shot offsets.

5) A new 1-D model was constructed and 3) was repeated until an acceptable match (maximum traveltime error less than $0.3 \mathrm{~ms}$ ) was obtained between the model and the data.

Figure 5 shows a plot of the 1-D velocity field computed for a line running through the well from west to east. Most units show very uniform velocities, indicating that the geologic structure within the zone imaged by the direct arrival (above the deepest hydrophone level) is relatively flat. This is consistent with the log interpretations of HSUs 2 and 3 . Note the extremely low velocity $(278 \mathrm{~m} / \mathrm{s})$ in the first ten meters. This velocity is less than the velocity of sound in air $(-330 \mathrm{~m} / \mathrm{s})$. This zone is probably responsible for the attenuation of the higher frequencies. Also note that there are two intervals below the top of the water table where the velocity is less than $1500 \mathrm{~m} / \mathrm{s}$ suggesting partial gas saturation. Instances of drilling into dry units below the water table, while infrequent, have been documented elsewhere on the LLNL site (Bainer, 1997). The two low-velocity units, centered at $36 \mathrm{~m}$ and $42 \mathrm{~m}$, correspond to the top of HSU-3 and the boundary between HSU-3a and HSU$3 b$. Lithologically these units are medium to coarse grained gravels but are separated hydrualically by low velocity clay.

The large velocity contrast between the near-surface soil and the deeper sediments creates severe raybending at the water table. Raytrace modeling through the velocity field suggests that the raypath linking the top of the water table and the surface is nearly vertical. Consequently, the raypaths created below the water table are equivalent to the raypaths created by having the source located at a depth of $25 \mathrm{~m}$ and arrival incidence angles in the range from 30 to 70 degrees for source offsets greater than $25 \mathrm{~m}$. These wide angles probably account for the difficulty in interpreting the wavefield for the longer-offset source positions. It is well known that wavefields become increasingly complex with increasing offset and velocity contrast.

\section{Reflection Imaging}

The objective horizon for reflection imaging was HSU-4, intersected between 52.7 and $56.3 \mathrm{~m}$ in well $\mathrm{w}-1206$. This unit was below the deepest hydrophone position $(48.5 \mathrm{~m})$ and therefore could not be imaged with direct rays. To isolate the primary reflection arrivals from the direct arrivals and the tube waves, wavefield separation in both the common source and common receiver domain was utilized. In the common source domain, the direct arrival was aligned and then a constrained eigenvector filter was used 
to attenuate the direct arrival (Mars and Rector, 1995). The constrained eigenvector approach was used to minimize edge effects associated with median filters. Following this filter, downgoing and upgoing tube waves were attenuated with an $\mathrm{f}-\mathrm{kz}$ fan filter. The data were then sorted into common receiver domain and an $\mathrm{f}-\mathrm{kq}$ fan filter (where $\mathrm{q}$ represents azimuthal angle) was applied to enhance arrivals with coherency from azimuth to azimuth. No trace padding was needed for the $\mathrm{f}-\mathrm{kq}$ fan filter, as the data are truly periodic in $\mathrm{q}$. The periodic nature of the data means that for spatial frequencies adequately sampled by the 10 degree azimuthal sampling rate, the discrete fourier transform over azimuth is equivalent to the continuous fourier transform over azimuth. In other words, windowing effects should be non-existent in the azimuthal transform domain.

Figure 6 shows the separated reflection wavefield at 45 degree azimuthal increments with the gamma ray log and the conductivity log synthetics stretched to two-way time. The reflection data have been shifted to an approximate two-way time using the direct arrival time picks. The data represent the stacks of the $15 \mathrm{~m}$, the $20 \mathrm{~m}$ and the $25 \mathrm{~m}$ offsets. No data was acquired for the $\mathrm{W}$ and NW directions at these offsets. Two strong reflectors are apparent. The first peak intersects the direct arrival at about $36 \mathrm{~m}$, and corresponds to the top of HSU-3. The second peak does not intersect the direct arrival and it is difficult to track this reflection below about $47 \mathrm{~m}$ where upgoing tube wave interferes with the reflection arrival. This reflection arrival also appears to pull up as hydrophone positions become shallower, indicating that there is substantial dip on the horizon. Two-dimensional (2D) raytrace modeling indicates that the dip, if assumed planar, is about 25 degrees. Based on this apparent dip and the arrival time at the deepest hydrophone, along with the good log correlation we estimate that this reflection is associated with HSU-4. Detailed structural analysis of this reflection was not performed because we did not have access to a 3-D raytracing code. However, based on the traveltimes and moveouts, it appears that this reflection dips up to the NE. The maximum moveout is observed in this direction, and the minimum moveout is observed to the SW, which is consistent with pre-image moveout analysis of dipping beds (Hardage, 1985). The HSU-4 unit reflection appears to be continuous over the lateral zone covered by the VSP survey (roughly 10-15 $\mathrm{m}$ from the borehole).

\section{Conclusions}

VSP conducted at well W-1206 successfully imaged the structure and continuity of the major hydrostratigraphic units of interest. In particular reflection imaging of the HSU-4 unit refined well log interpretations by characterizing the magnitude and direction of structural dip. Unusually low $\mathrm{P}$-wave velocities were discovered at $\mathrm{W}-1206$, particularly in the shallowest 10 $\mathrm{m}$ where the formation velocity was less than $300 \mathrm{~m} / \mathrm{s}$. Below the top of the water table units with formation velocities lower than $1500 \mathrm{~m} / \mathrm{s}$ (water 
velocity) were found. These units, approximately 1-2 $\mathrm{m}$ thick, corresponded to interpreted hydrostratigraphic boundaries.

\section{References}

Milligan, P. A., Rector, J.W., Bainer, B., 1997, Shallow Hydrophone VSP at a Bay Margin Site, Geophysics, in press.

Bainer, B., 1997, personal communication.

Mars, J., and Rector, J.W., 1995, Constrained eigenvectors: a means to separate aliased arrivals, Presented at the 59th Annual SEG meeting, Houston, Texas.

Hardage, B. A., 1985, Vertical Seismic Profling: Part A Principles, McGraw Hill Book Co. 


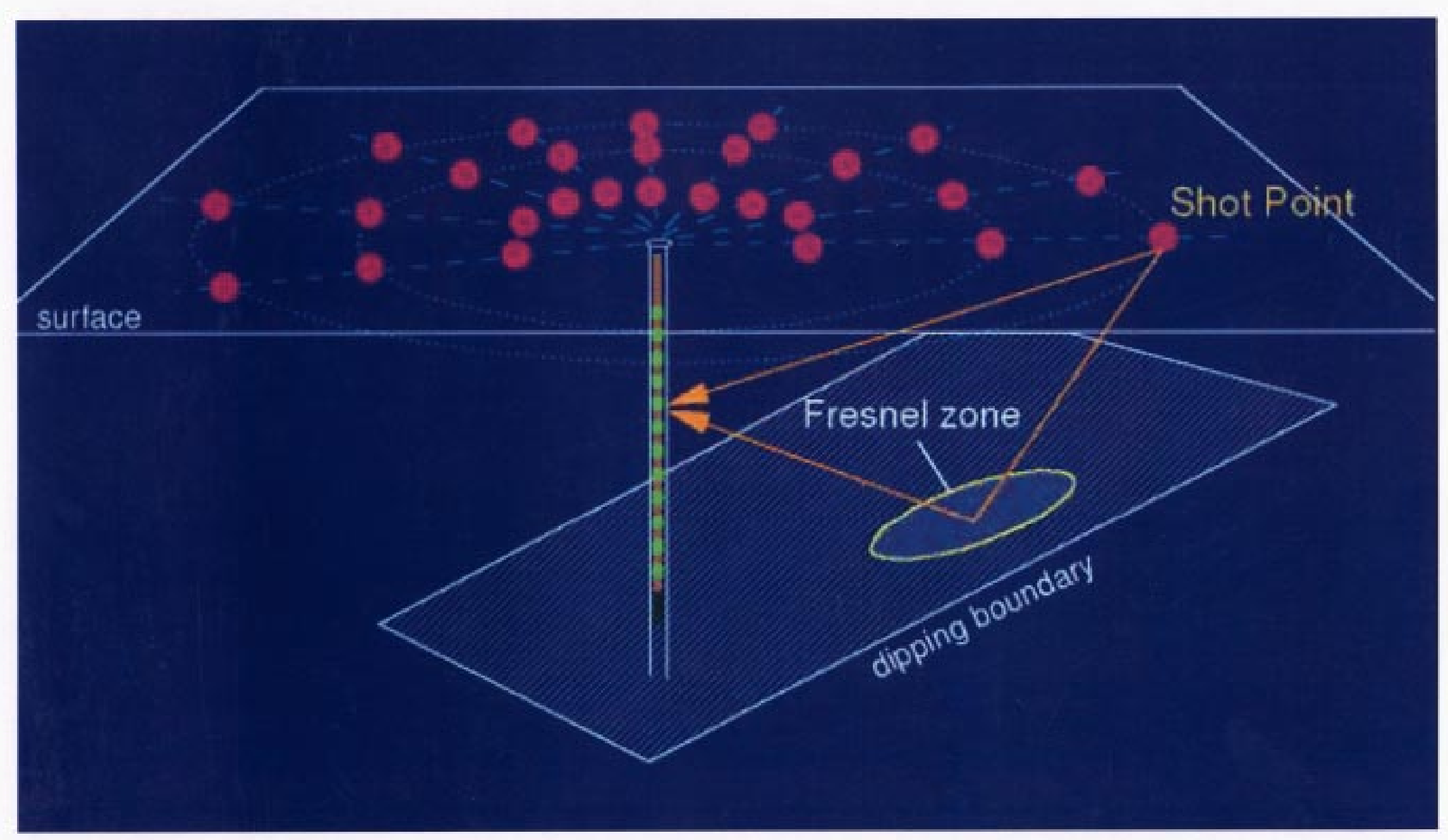

Figure 1. 3-D VSP geometry. 


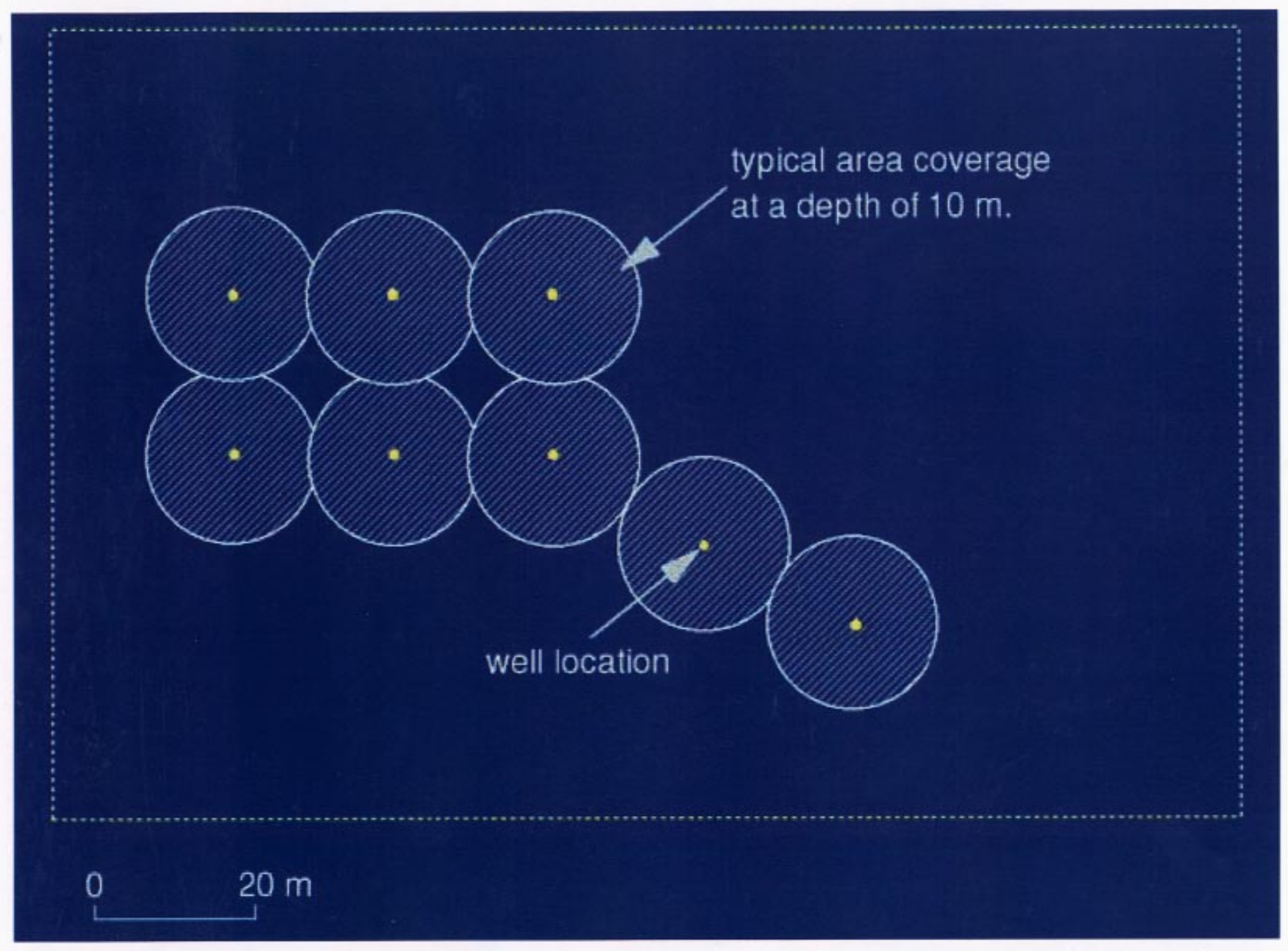

Figure 2. 3-D VSP site characterization using multiple wells. 


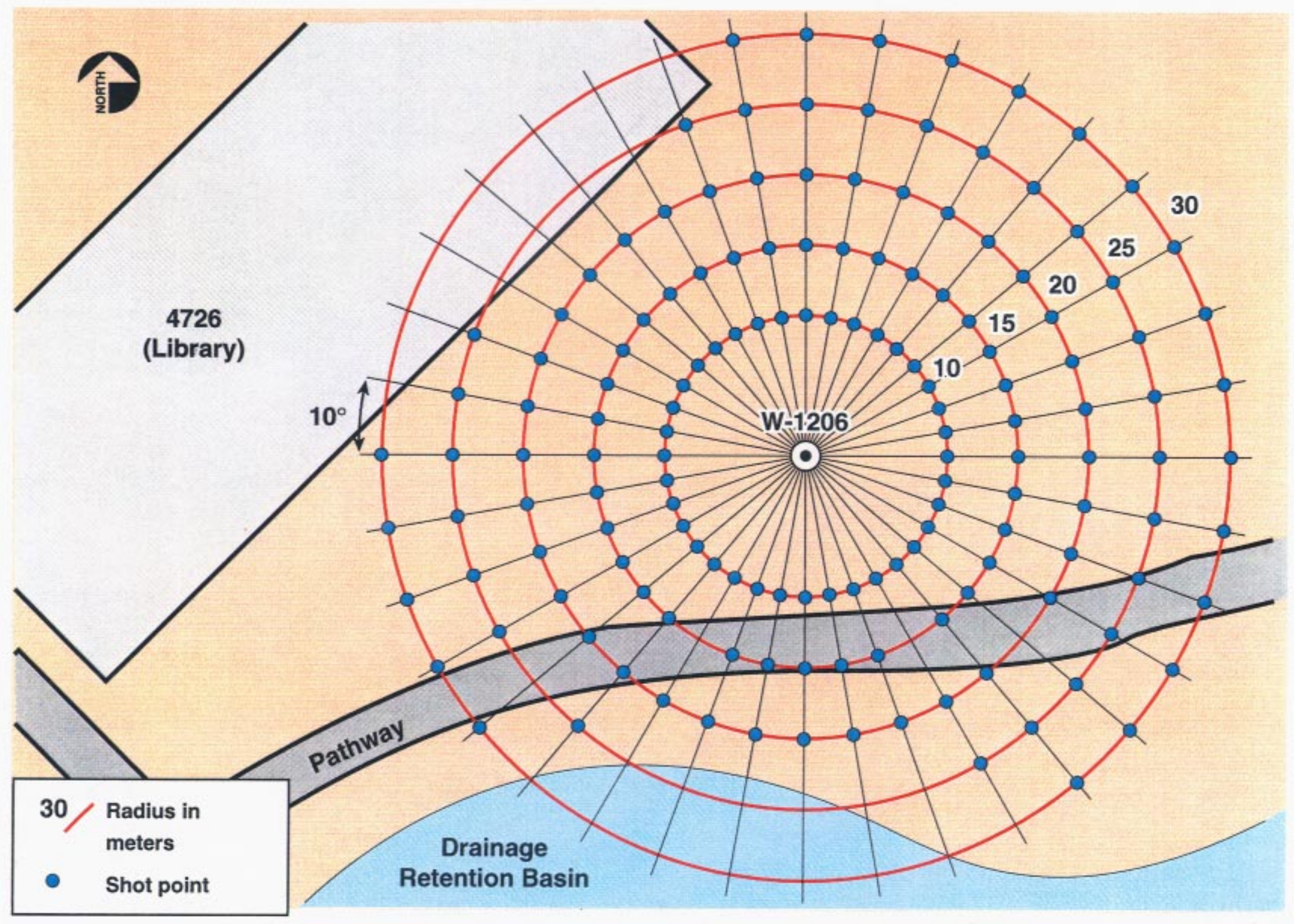

Figure 3. Map view of study area. Dots represent 3-D VSP source positions that were collected. 
A

Southwest

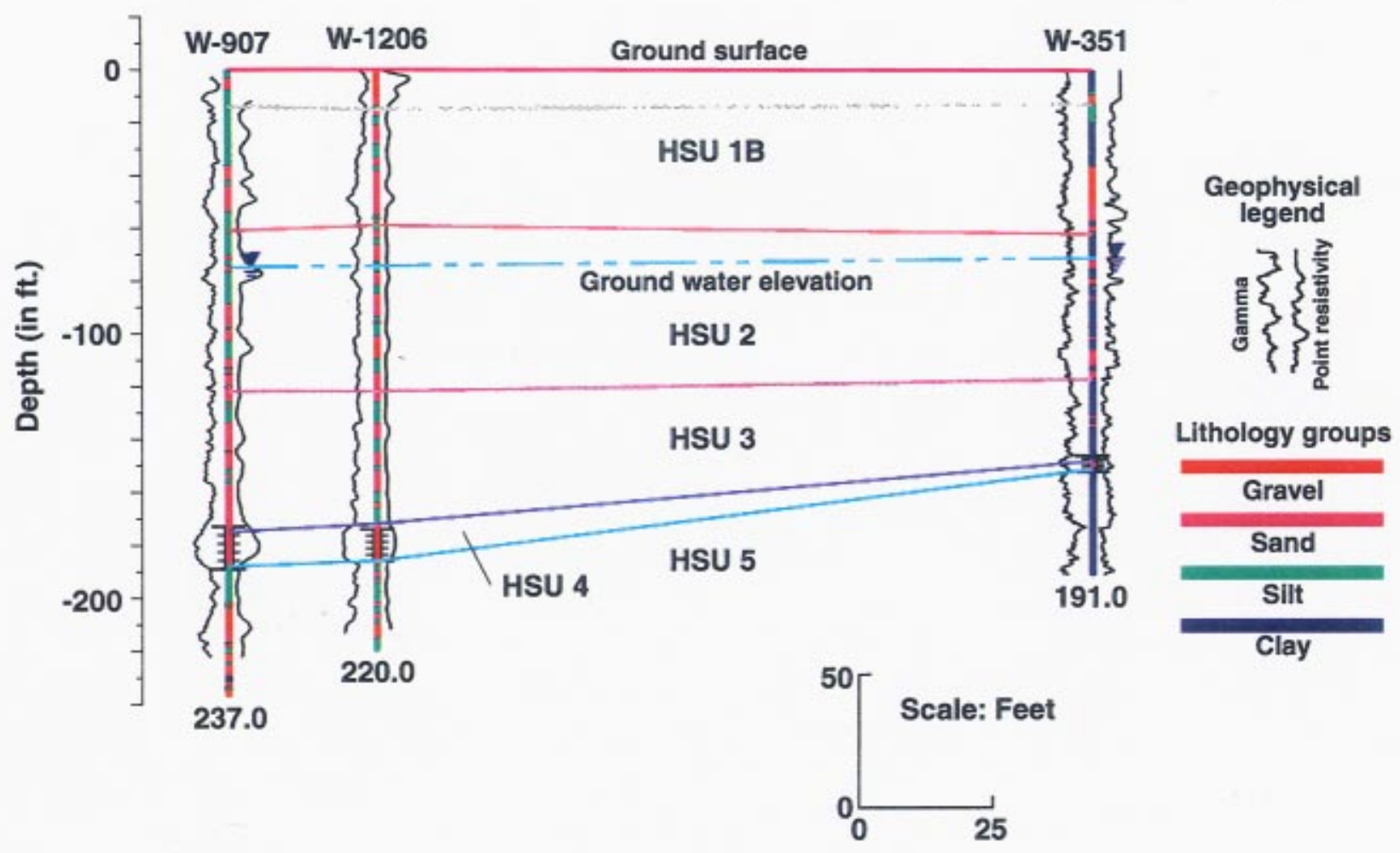

Figure 4. A-A' cross-section across study area with gamma ray and resistivity logs illustrating interpreted hydrostratigraphic units. 


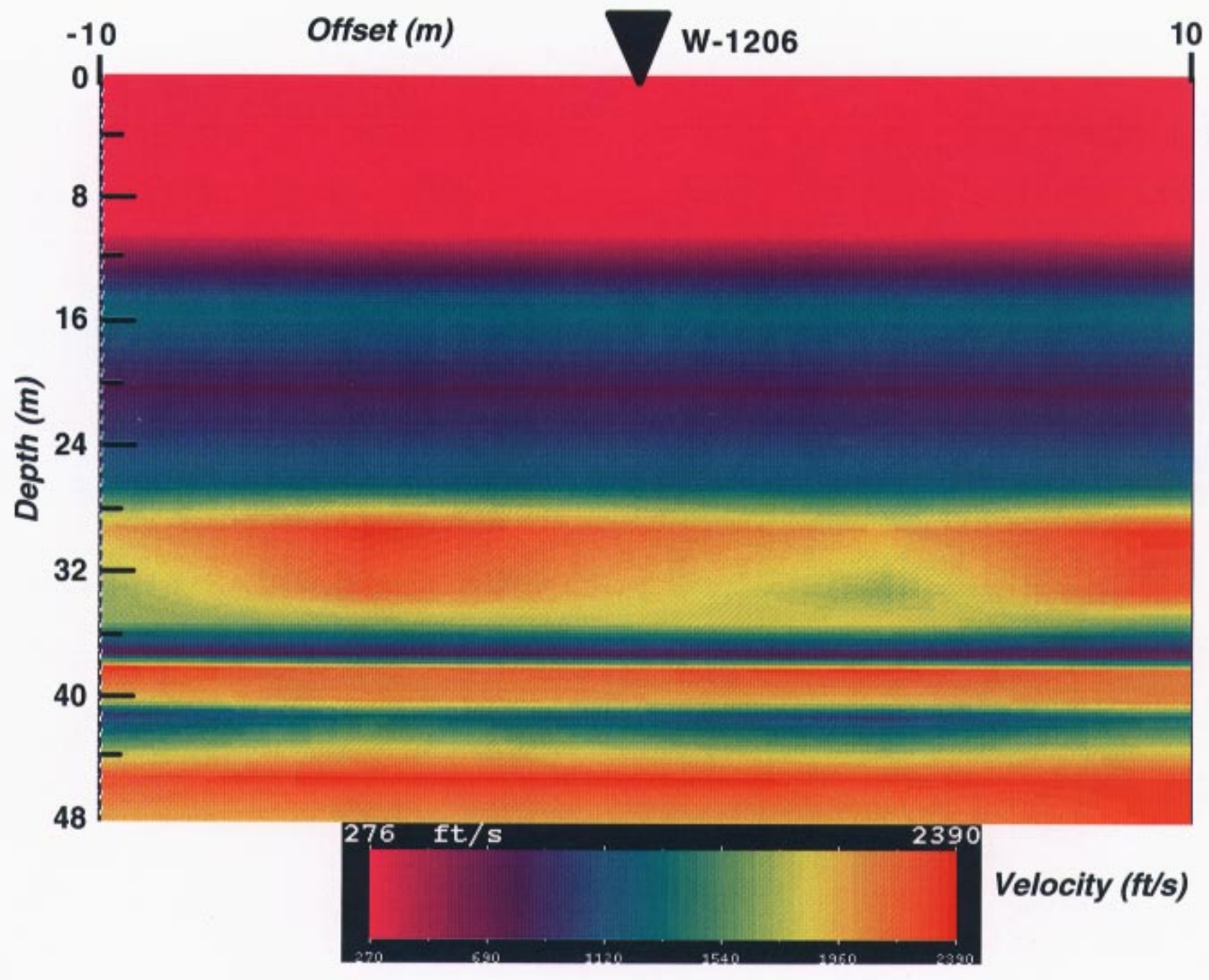

Figure 5. Representative velocity field along E-W cross-section. 


\section{GR Cond}

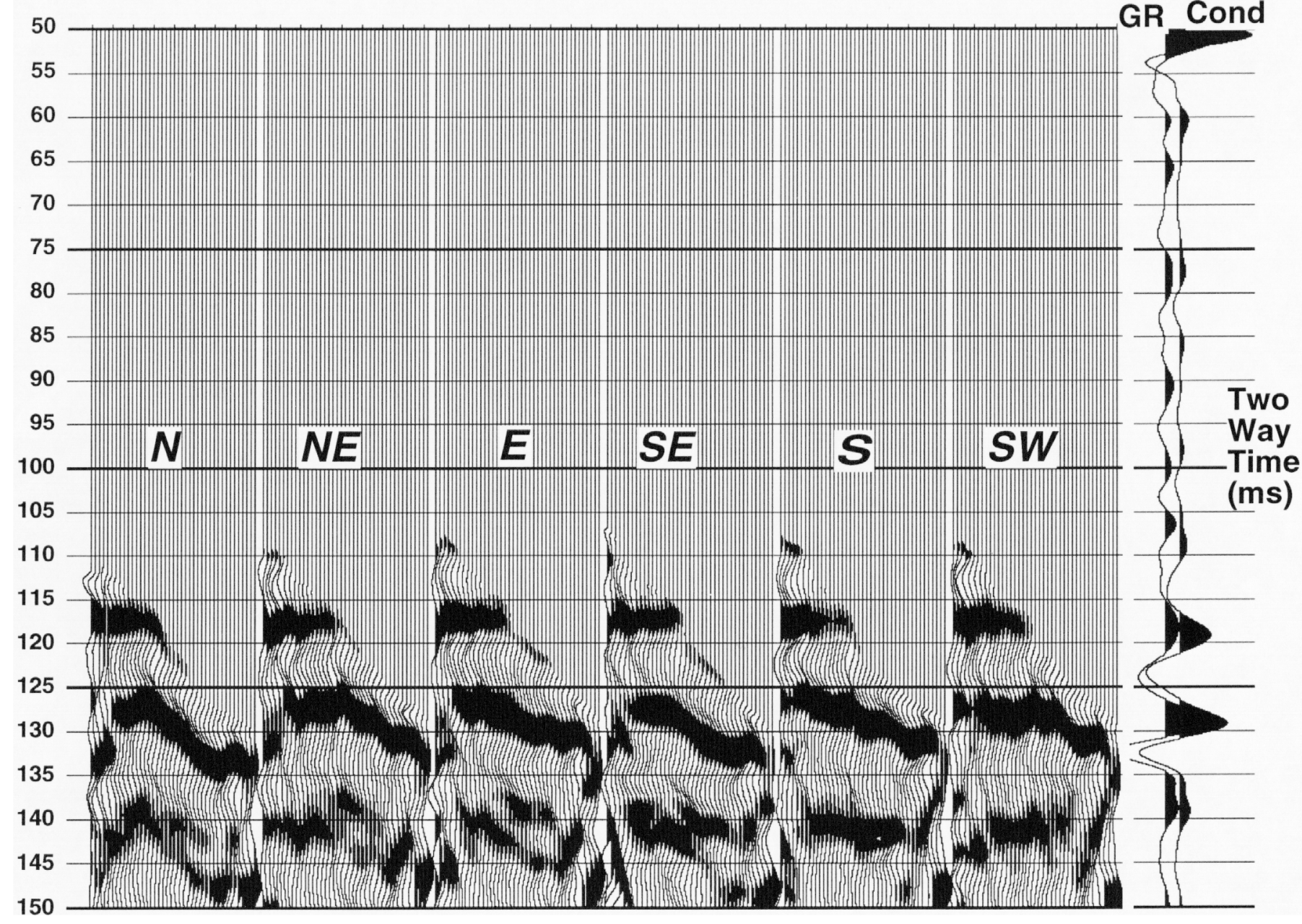

Figure 6. Stacked reflection series from selected azimuths ranging from $\mathrm{N}$ to SW (proceeding clockwise) along with synthetics produced from gamma and conductivity logs. 


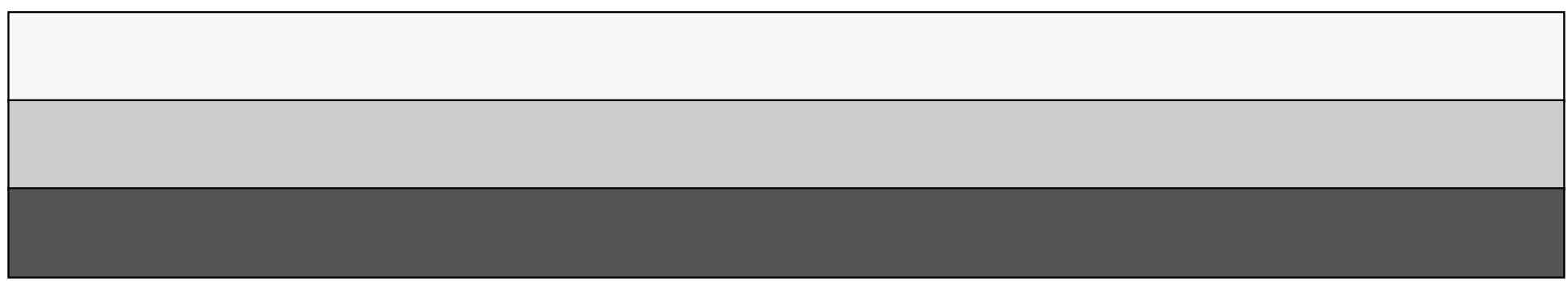

